\title{
EXPERIMENTAL MEASURES OF THE EFFECTIVE HEAT TRANSFER COEFFICIENTS IN AIR BLAST FREEZERS FOR THE PROCESSING OF FRUIT PULPS
}

\author{
J. V. Resende \\ Universidade Federal de Lavras \\ Departamento de Ciências Exatas \\ Caixa Postal 37 \\ Campus Universitário \\ 37200-000, Lavras, Minas Gerais, Brasil \\ jvresen@bol.com.br \\ V. Silveira Junior and L. Neves Filho \\ Universidade Estadual de Campinas \\ Caixa Postal 6121 \\ ABSTRACT \\ The effective surface heat transfer coefficients during air blast freezing of plastic \\ polyethylene packages containing fruit pulp models conditioned inside multi \\ layer boxes were evaluated under conditions encountered in commercial \\ practice. The results were presented as dimensionless correlations based on \\ hydraulic diameter of the rectangular ducts. The effects on the surface heat \\ transfer coefficient of the air temperature, air velocity, transducer position inside \\ the boxes and box position in the pillage on the surface were analyzed. The \\ results show: the effect of air-cooling temperature on the surface heat transfer is \\ negligible in the range encountered in blast freezing practice. The effective \\ surface heat transfer coefficients predicted by the non-dimensional correlations \\ based on hydraulic diameter was successfully used to represent the bed \\ irregularities, mainly in arrays of 5 and 3 layers. The effective surface heat \\ transfer coefficients varied according to the position between the top and the \\ Cid. Universitária Zeferino Vaz - \\ 13083-970, Campinas, São Paulo, Brasil \\ bottom of the boxes and was influenced by the number of layers in the arrays.
}

vivaldo@ceres.fea.unicamp.br neveslin@ceres.fea.unicamp.br

\section{INTRODUCTION}

The global heat transfer coefficient between the surface of the product and the cooling air is an important parameter in the studies of the freezing time of foodstuffs. In systems in which the means of transference is cold air, as in the air blast freezers, one of the factors that control the freezing rate is the convective heat coefficient (Chavarria and Heldman, 1984).

In normal conditions, the heat transfer coefficients vary with the temperature, air humidity and mainly with the air velocity. In the freezing of particulate systems (fixed or fluidized bed), the heat transfer coefficients still depend on the bed porosity and air flow properties.

In accordance with Kondjoyan and Daudin (1997), convective heat transfer must be distinguished from effective heat transfer coefficient. Beyond the heat transferred by convection, the last includes the heat transferred by conduction between the bodies in contact, radiation or by phase change, when this occurs.

Few experimental values of convective heat transfer coefficients had been obtained in the last years and frequently are related to a type of specific operation. The values of the coefficients supplied in the literature of engineering in the form of dimensionless numbers such as Nusselt in function of the Reynolds number for slab, cylinder or sphere are rarely used in models because they take the calculated values different of the experimental results (Kondjoyan et al., 1993). A great range of magnitudes for superficial heat transfer coefficients (" h ") were related. Nicolaï and De Baedemaeker (1996), cited typical values of $300 \mathrm{~W} / \mathrm{m}^{20} \mathrm{C}$ obtained during the hydrocooling of fruits and vegetables while in the cooling with forced air, " $\mathbf{h}$ " can vary between 8 and $68 \mathrm{~W} / \mathrm{m}^{20} \mathrm{C}$. Information involving values of " $\mathbf{h} "$ for the food surfaces with regular shapes meet available in literature (Arce and Sweat, 1980; Lind, 1988; Cleland, 1990; LeBlanc et al., 1990 a,b; Kondjoyan and Daudin, 1993; Cleland et all., 1994; Salvadori et al., 1996).

Values of " $\mathbf{h} "$ associates to the different geometric shapes, surfaces and arrays of the package spaces have not been determined. The determination of the heat transfer coefficients around of foodstuffs still has been a restricted topic to the processing specific conditions. For the freezing of foodstuffs in boxes, literature values have shown that the surface heat transfer coefficients vary when the measure is made in different locations along of the product layers inside of the boxes. Thus, values of the coefficients are different between the superior and inferior layers of product in the box and, therefore, studies that ignore these variations must be 


\section{TECNOLOGIA/TECHNOLOGY}

dealt with sufficient care (Pham and Willix, 1985; Mannaperuma et al., 1994 a,b). In this work the objectives were: 1) To develop a methodology for the estimate of the effective heat transfer coefficients $\left(\mathrm{h}_{\text {effective }}\right)$ applicable to the fruit pulp freezing packed in polyethylene bags $(100 \mathrm{~g})$ and conditioned in boxes, examining the behavior of the temperature distribution, of the variables in the unsteady state, evaluating it in the thermal center with a metallic transducer. 2) To characterize the process through the determination of the effective heat transfer coefficients in a air blast freezer with horizontal air flow. 3) To quantify the effective heat transfer coefficients, taking in account the location between the product layers packed inside of the boxes.

\section{METHODS AND MATERIALS}

\section{Construction of the metallic transducer for the $\mathbf{h}_{\text {effective }}$ determination}

Transducer consists of an aluminum slab with the same dimensions of the samples in which was made five holes where had been inserted thermocouples type $\mathrm{T}$ (cooper-constantan, diameter 32 AWG). The empty spaces around of the thermocouples inside of the slab were filled with thermal paste to prevent the formation of air bags inside of the transducer. The build up (transducer + thermocouples) was located in the boxes containing the samples in pre-established locations for to quantify the effective heat transfer coefficients values and its variations along of the different positions (inferior and superior layers) in the product layers in the boxes pillage. To assure the unidirectional heat flux, the transducer was coated with expanded polystyrene thermal insulator (Fig. 1). To each experimental assay the position of the transducer was varied inside of each box of the piling up, with arrays of 3,5 and 7 product layers.

\section{Product freezing process}

2.1. Elaboration of the samples before the freezing process

The samples were constituted of composite solutions model by $0.5 \%$ (weight/volume of $\mathrm{H} 2 \mathrm{O}$ ) of Kcarrageenan (DANISCO) and 10\% (weight/volume H2O) of sucrose, packed in polyethylene bags of 100 grams.
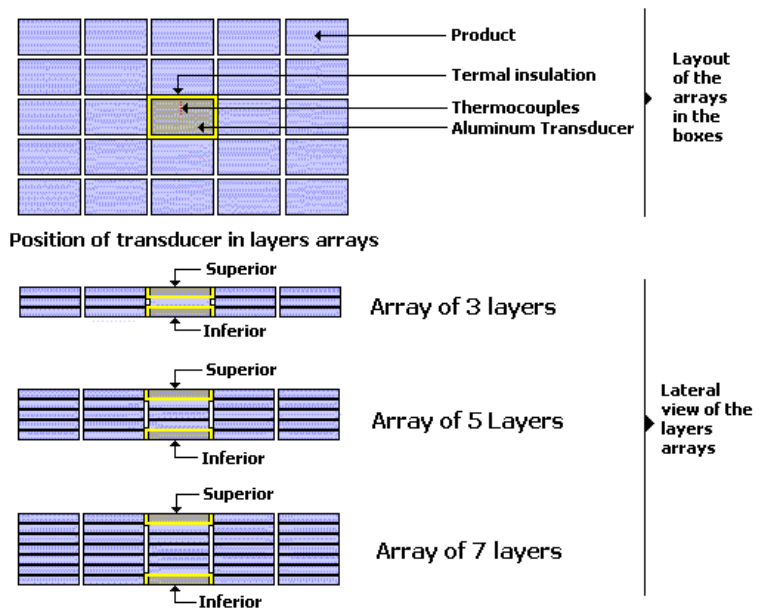

Figure 1. Position of metallic transducer in the layers arrays of product inside of the boxes.

Previously to the freezing process, to create a appreciable difference between transducer temperatures and the cooling air temperature in the freezing chamber and to assure a uniformity and thermal homogeneity of the samples initial temperatures in the boxes, these were immersed in a tank with agitation with continuous water stream with constant temperature $\left(26^{\circ} \mathrm{C}\right)$ proceeding from the refrigeration system by a period of 3 hours. Quickly, the samples were organized in arrays of 7, 5 or 3 layers in the boxes, and, the transducer was located between the samples and the boxes lead for the freezing chamber.

\subsection{Freezing of the product}

After to reach the stabilization of the equipment in the operating temperature, three boxes containing the samples and the transducer, were piled up in the freezing chamber. To prevent the formation of preferential channels, expanded polystyrene boards were placed in the lateral sections of the boxes making with that all the air flow in the chamber pass among the empty spaces of the boxes contends the product. The temperature monitoring of the transdu-cer was performed in 1 minute intervals.

\section{Measures of the air velocity}

The measures of the air velocity were made by a hot wire anemometer (TSI, the USA, Model 8330-M) with readings in all the section of the chamber in each assay. The air flow rate in each run was obtained by numerical integration of the air velocities distributions (Resende, 2001) along of the freezing chamber section. 


\section{Experimental planning}

Table 1 shows the levels of the factors of each variable, according with an factorial planning, being that the coordinates of the transducer and boxes positions are clarified in Fig. 2 .

Table 1. Factors e factors levels considered in the experiment planning.

\begin{tabular}{|l|c|c|c|}
\hline \multirow{2}{*}{ Factors } & \multicolumn{3}{|c|}{ Factors levels } \\
\cline { 2 - 4 } & + & 0 & - \\
\hline 1 - Air Temperature $\left({ }^{\circ} \mathrm{C}\right)$ & Level 1 (- & Level 2 (- & Level 3 (- \\
& $30)$ & $25)$ & $20)$ \\
\hline 2- Product amount (Layers/box) & 7 & 5 & 3 \\
\hline 3- Box Position & Box 3 & Box 2 & Box 1 \\
\hline 4- Location inside of the box P(x,y) & Superior & - & Inferior \\
\hline
\end{tabular}

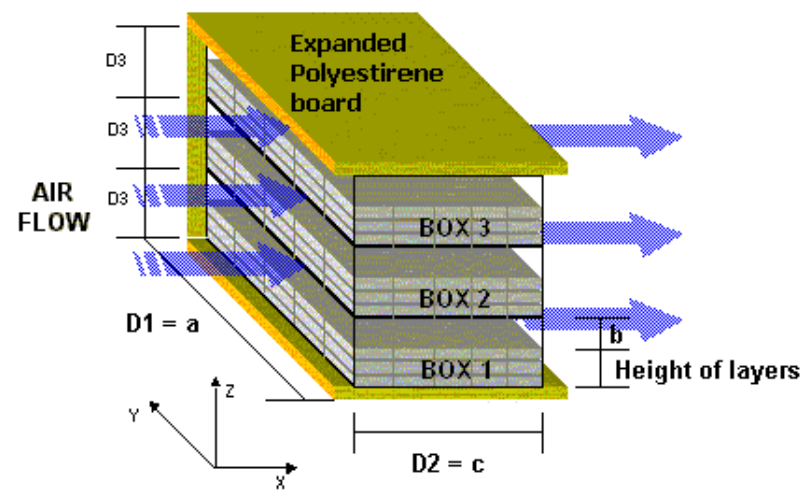

Figure 2. Systems of coordinates and boxes position in the freezing chamber.

\section{Calculation of the heat transfer coefficients}

Calculations of the heat transfer coefficients were made after the attainment of the cooling curves of the metallic transducer. The angular coefficients $\left(S_{2}\right)$ of the linear regression of $\ln \left[\left(T_{m}-T_{a i r}\right) /\left(T_{i}-T_{a i r}\right)\right]$ versus $t$ were calculated and used in the Eq. (1) to find the effective heat transfer coefficients. $T_{m}$ is obtained by the average values from the readings of the five thermocouples located inside of the metallic transducer and $T_{i}$ is the initial temperature of the aluminum slab.

$$
h_{\text {effective }}=\frac{-\rho_{A l} V C_{P A l} S_{2}}{A}
$$

where $\mathrm{V}$ is the volume of the transducer $\left(\mathrm{m}^{3}\right), \mathrm{A}$ is the superficial area of the transducer $\left(\mathrm{m}^{2}\right), \rho_{\mathrm{Al}}$ is the density of aluminum $\left(\mathrm{kg} / \mathrm{m}^{3}\right)$ and $\mathrm{Cp}_{\mathrm{Al}}$ is the specific heat of aluminum $(\mathrm{J} / \mathrm{kg} \mathrm{K})$. The values of $\mathrm{V}, \mathrm{Cp}_{\mathrm{Al}}$ and $\rho_{\mathrm{Al}}$ for the aluminum transducer used for the calculation of the effective coefficient are presented in Table 2.

Table 2 Geometric parameters and thermophysical properties of the aluminum transducer used for the determination of the effective heat transfer coefficient.

\begin{tabular}{|c|c|c|c|c|c|}
\hline \multicolumn{6}{|c|}{ Geometric Parameters } \\
\hline Length (m) & \multicolumn{2}{|c|}{ Width (m) } & $\begin{array}{l}\text { Thickness } \\
(\mathrm{m})\end{array}$ & Area $\left(\mathrm{m}^{2}\right)$ & Volume $\left(\mathrm{m}^{3}\right)$ \\
\hline 0,1214 & \multicolumn{2}{|r|}{0,0796} & 0,0160 & $9,66 \times 10^{-3}$ & $1,545 \times 10^{-4}$ \\
\hline \multicolumn{6}{|c|}{ Thermophysical properties of the aluminum ${ }^{\star}(293 \mathrm{~K})$} \\
\hline \multicolumn{2}{|c|}{ Density, $\rho_{\mathrm{Al}}\left(\mathrm{kg} / \mathrm{m}^{3}\right)$} & \multicolumn{2}{|c|}{$\begin{array}{c}\text { Specific heat, } \mathrm{Cp}_{\mathrm{Al}} \\
(\mathrm{J} / \mathrm{kgK})\end{array}$} & \multicolumn{2}{|c|}{$\begin{array}{c}\text { Thermal conductivity, } \mathrm{k}_{\mathrm{Al}} \\
(\mathrm{W} / \mathrm{mK})\end{array}$} \\
\hline \multicolumn{2}{|l|}{2701,1} & \multicolumn{2}{|c|}{904} & \multicolumn{2}{|c|}{229} \\
\hline
\end{tabular}

\section{Dimensionless correlations for determination of the effective heat transfer coefficients}

The metallic transducer inside of the box was placed in the central location and in the superior and inferior positions of product layers arrays. In these positions, the aluminum slab can be considered as part of the wall of a rectangular duct of sides "a", "b" and length "c" (Fig. 2).

Dimension " b " is evaluated by the difference between the box height (D3) (Fig.2) and the bed height, and is established by the layers number of the product packages arrays inside of the boxes. The considered rectangular ducts, understood the empty spaces between the product layers arrays inside of each box and the inferior side (deep) of the box located immediately above in the pillage, where air was forced to pass (preferential channels). The air velocity (v), passing through these channels, was approached through the relation between the air flow rate and the available area for the air flow $\left(\mathrm{A}_{\mathrm{E}}\right)$ as the expression:

$$
v=\frac{{ }^{*}}{A_{E}}
$$

These approaches were used for the attainment of correlations Nusselt versus Reynolds from the experimental values of the effective heat transfer coefficients of the previous section (5) and the numbers Reynolds $\left(\mathrm{Re}_{\mathrm{DH}}\right)$ and Nusselt $\left(\mathrm{Nu}_{\mathrm{DH}}\right)$ were calculated from the hydraulic diameter $\left(\mathrm{D}_{\mathrm{H}}\right)$ by the following relations (Reinick and Schwartzberg, 1985).

$$
\begin{aligned}
& \mathrm{Nu}=0,116\left[(\mathrm{Re})^{2 / 3}-125\right] \operatorname{Pr}^{1 / 3}\left[1+\left(\mathrm{D}_{\mathrm{H}} / \mathrm{L}^{\prime}\right)^{2 / 3}\right] \\
& \text { for } 2000<\operatorname{Re}<10000 \text { and } \\
& \mathrm{Nu}=0,023(\mathrm{Re})^{0,8} \operatorname{Pr}^{1 / 3} \\
& \text { for } \operatorname{Re} \geq 10000 \text {. }
\end{aligned}
$$

When $L^{\prime} / D_{H} \leq 60, h=h_{2(e q)}\left[1+1,4\left(D_{H} / L^{\prime}\right)\right.$, where $h_{2(e q)}$ is the value obtained from the Eq. (3) or (4) and L ' is the duct length.

For a rectangular duct of sides, $b$; the hydraulic radius $\left(\mathrm{R}_{\mathrm{H}}\right)$ and the hydraulic diameter $\left(D_{H}\right)$ of a channel are given by the following equations (Perry and Green, 1984):

$$
\begin{aligned}
\mathrm{R}_{\mathrm{H}} & =\frac{\mathrm{ab}}{2(\mathrm{a}+\mathrm{b})} \\
\mathrm{D}_{\mathrm{H}} & =\frac{2 \mathrm{ab}}{(\mathrm{a}+\mathrm{b})}
\end{aligned}
$$


where the dimensions $\mathrm{a}$ and the $\mathrm{b}$ are those presented in Fig. 2.

Considering the dimensions of the samples presented in Table 3, the hydraulic diameter of the considered rectangular ducts had been obtained for experiments with 7, 5 and 3 layers of products (Table 3).

Table 3. Parameters used for calculation of hydraulic diameter.

\begin{tabular}{cccc}
\hline $\mathbf{N}^{\mathbf{D}}$ of Layers & Side $\mathbf{a}(\mathbf{m})$ & Side b $(\mathbf{m})$ & $\begin{array}{c}\text { Hydraulic Diameter } \\
\mathbf{D}_{\mathbf{H}}(\mathbf{m})\end{array}$ \\
\hline 7 & 0.585 & 0.013 & 0.0254 \\
5 & 0.585 & 0.045 & 0.0836 \\
3 & 0.585 & 0.077 & 0.1361 \\
\hline
\end{tabular}

\section{RESULTS AND DISCUSSION}

\section{Curves of cooling}

Five curves time-temperatures were obtained in each freezing experiments, one for each thermocouples located in the different positions inside of the metallic transducer. Figure 3 shows the dimensionless temperatures obtained from the readings of the thermocouples in the transducer. The small Biot value characteristic of the transducer represents the case in which the internal resistance is very small e exists bigger capacity to the heat transfer by conduction of that by convection. In this case, the convection is the phenomenon that restricts the heat transference and the temperature gradients in the metallic transducer are sufficiently small as observed in Fig. 3. A high degree of uniformity of the aluminum slab is observed, by the small variation of the temperature for thermocouples located in different positions of the transducer. Therefore the average temperature $\left(T_{\mathrm{m}}\right)$, can be substituted by only one temperature probe located in the transducer center.

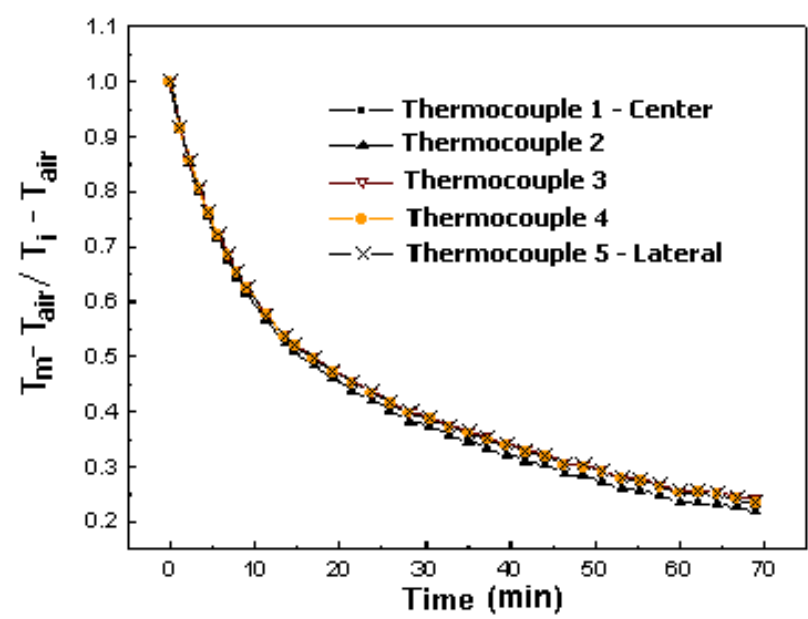

Figure 3. Dimensionless temperatures from the readings in the transducer

The graph of Fig. 4 shows the cooling curves of the transducer, when located in the superior layer of the array with the exposed surface in direct contact with the fluid in movement, and, in the inferior layer of the array with the heat transfer surface in contact with the deep of the box. The deep of the box is composite of a plastic material with holes that reduce the exposition area necessary for the heat transfer and limits the direct contact of the surface of the metallic transducer with the cooling air.

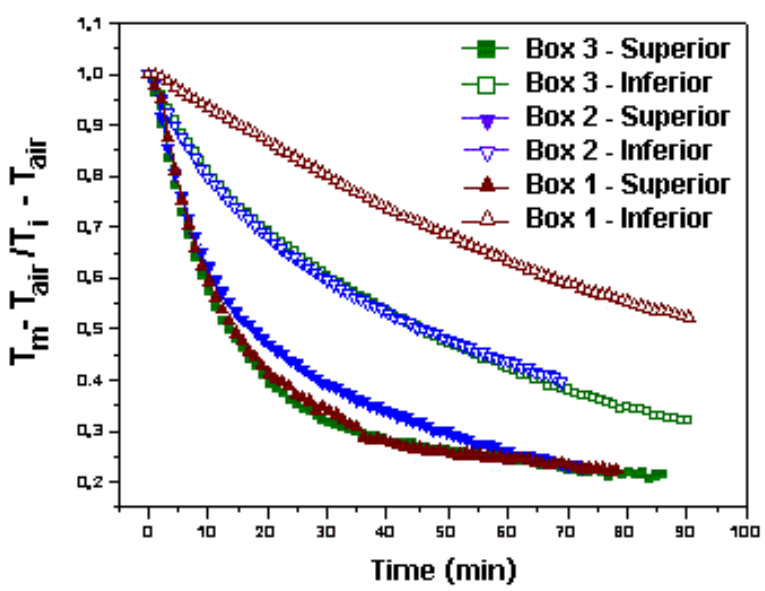

Figure 4. Experimental curves for the metallic transducer located in different positions inside of the boxes for assays with arrays of 5 layers.

It is observed in Fig. 4 that the boundary conditions are asymmetrical when is made an analysis of the cooling curves in individual boxes, and this effect is produced by the resistance that the material of the deep of the box offers to the heat transfer differentiating the temperature profiles of the inferior and superior layers.

\section{Determination of the effective heat transfer} coefficients

Figure 5 presents the graph of the logarithm of the dimensionless temperature $\left(\mathrm{T}_{\mathrm{m}}-\mathrm{T}_{\text {air }}\right) /\left(\mathrm{T}_{\mathrm{i}}-\mathrm{T}_{\text {air }}\right)$ versus time for the determination of the values of the heat transfer coefficients for an array of 5 layers of product in levels 1,2 and 3 of air temperature.

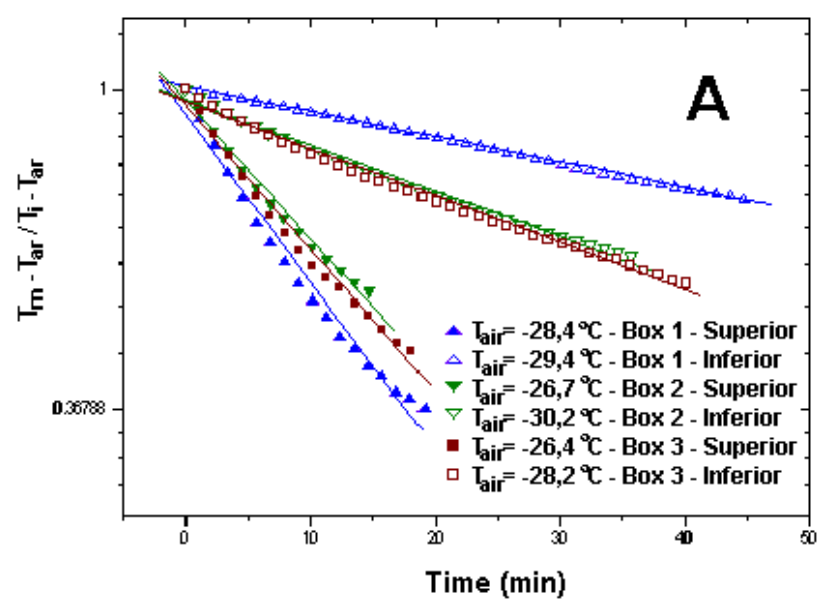



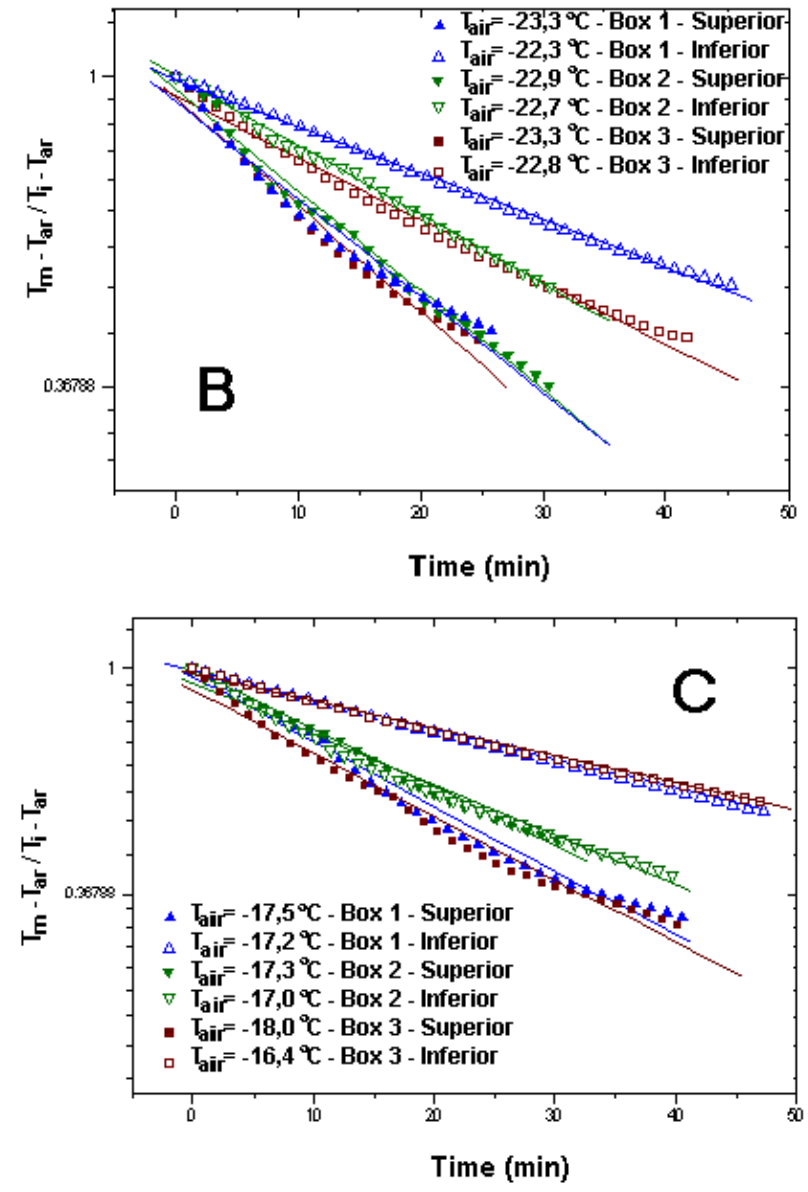

FIGURE 5. Angular coefficient of the curves for measures of the heat transfer coefficients for arrays of 5 layers in the same level of temperature. (A) Level 1, (B) Level and 2 (C) Level 3.

These were made from the data of cooling during the period where the air temperature and thermal conductivity of the samples in the boxes were practically kept constant.

The values of the effective heat transfer coefficients obtained for all experimental assays from the metallic transducer located in the inferior and superior layers of the product arrays inside of the boxes are presented in Tab 4.

\section{Experimental Nusselt numbers and analysis of the results and correlations}

Parameters involving the position of the metallic transducer in the product layers arrays in the boxes $(\mathrm{P}<0,01)$, the number of layers in the arrays $(\mathrm{P}<0,05)$ and the position of the box in the piling up $(\mathrm{P}<0,01)$ and some interactions between these factors exert a significant influence on the values of the coefficients heat transfer coefficients obtained from the experiments, as observed in Tab. 5 .

Table 5 presents the variance analysis of the values of the experimental effective heat transfer coefficients presented in Tab. 4 for the main factors considered in the experimental planning.
Table 5 show that the air temperature does not exert a significant influence on the values obtained experimentally for the effective heat transfer coefficients. These results allow to restrict the influence of the temperature, to unify the correlations and to emphasize the dependence of this correlation of the air velocity and of the different type of experimental configurations. Therefore, the calculated values of $h_{\text {effective }}$ (Table 4 ) were adjusted for the attainment of the dimensionless Eq. (7) and (8) for the transducer located in the superior and inferior layers in the boxes, respectively.

For the superior layer: $\mathrm{Nu}=0,0158 \mathrm{Re}^{0,8143}$

For the inferior layer: $\mathrm{Nu}=0,0075 \mathrm{Re}^{0,8546}$

The curves shown in the graph of Fig. 6 represent the predictions obtained for these equations in comparison with the experimental results.

\section{Effect on the location of the metallic transducer in the boxes}

For analysis of the experimental results must be considered: a) the boxes individually, a great difference in the boundary conditions was observed; b) locations of the boxes in upper positions of the piling up (box 2 and box 3) that present similar or compatible experimental conditions (velocities and air temperatures); c) the box of the base of the piling up (box 1) that meets supported on a expanded polystyrene board that hindering the contact of the box with the current of cooling air acts as thermal insulator, reducing drastically the " heat transfer coefficients" in deep of the boxes to the values that are typical of the natural convection.

Analyzing the effective heat transfer coefficients in the positions inferior and superior of an individual box, also is observed a great difference with the biggest values when the transducer was located in the superior layer of the array of the layers in direct contact with the airflow. The graph of Fig. 7 shows the percentile differences $(\Delta \%)$ relative between the values of the heat transfer coefficients obtained from the transducer located in the superior and inferior layers of the box for the different configurations.

$$
\Delta \%=\frac{N u-N u_{\text {exp }}}{N u_{\text {exp }}}
$$




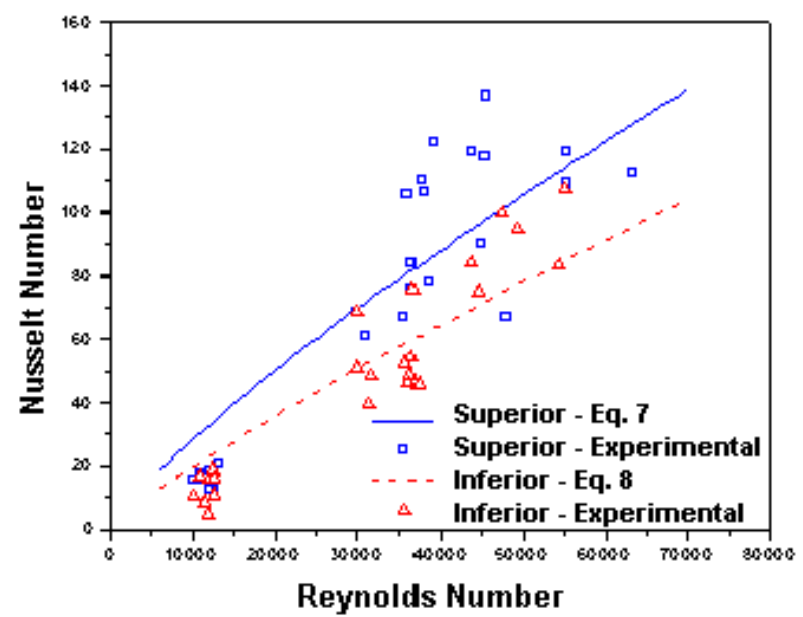

Figure 6. Correlations between the Reynolds and Nusselt numbers from the equations adjusted $\left(\mathrm{R}^{2}=\right.$ 0.998 and 0.999, Eqs. (7) and (8) for experiments with the transducer located in the superior and inferior layers of the product arrays inside of the boxes.
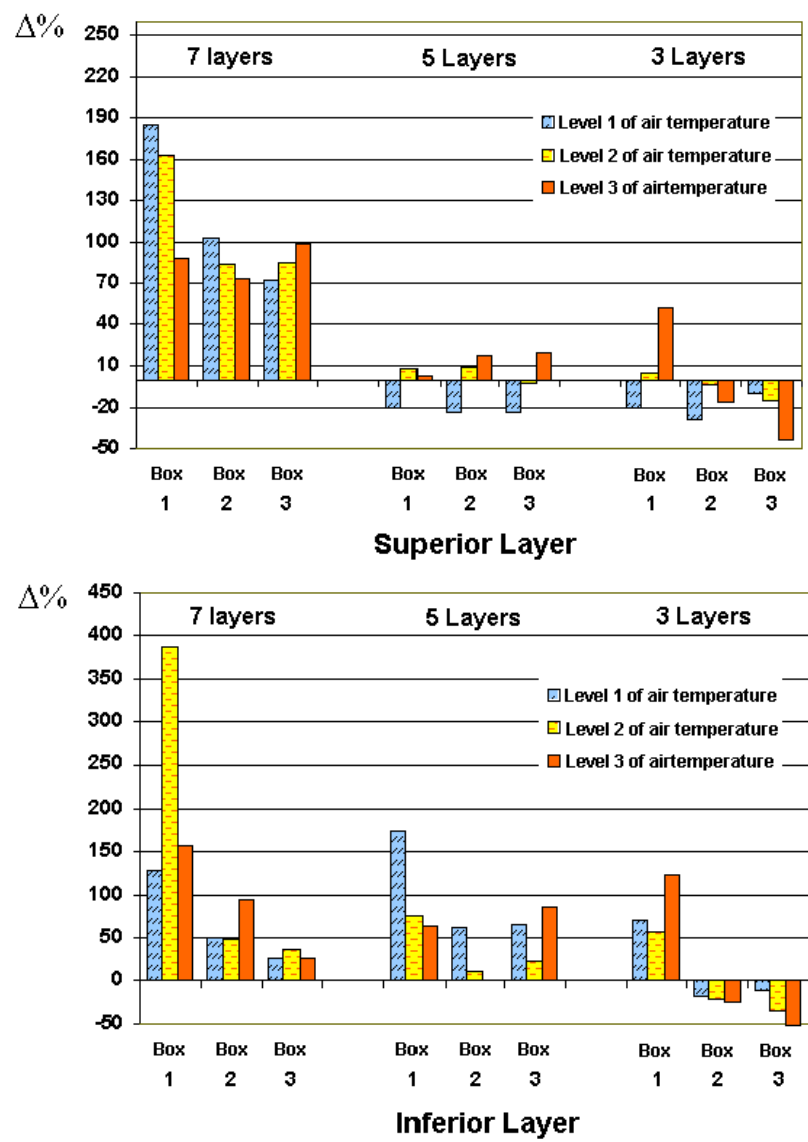

Figure 7. Difference between the values of Nusselt calculated from the Eqs. (7) and (8) and the values obtained from experimental results for the transducer located in the superior and inferior layers under different air flow conditions.

\section{Effect of the air temperature}

Temperature affects the air thermophysical properties that affect the dimensionless numbers Re, $\mathrm{Pr}$ and $\mathrm{Nu}$. When it is made data analyzes of the Tab. 5 constructed from experimental values, can be stated that the temperature of cooling air did not influence significantly the values of the effective heat transfer coefficients. This comment is the same of Mannaperuma et al. (1994b). The justification is that the temperature range found during the food freezing with forced air is very narrow and the effect of the temperature on the heat transfer coefficient by means of the changes of the air properties is very small. Therefore, the average values ( \%) (Eq. 9) of the difference between the values of Nusselt calculated by the equations based on the hydraulic diameter (Reinick and Schwartzberg, 1985) and the experimental values for the three configurations types can be reevaluated and are shown in Fig. 8.

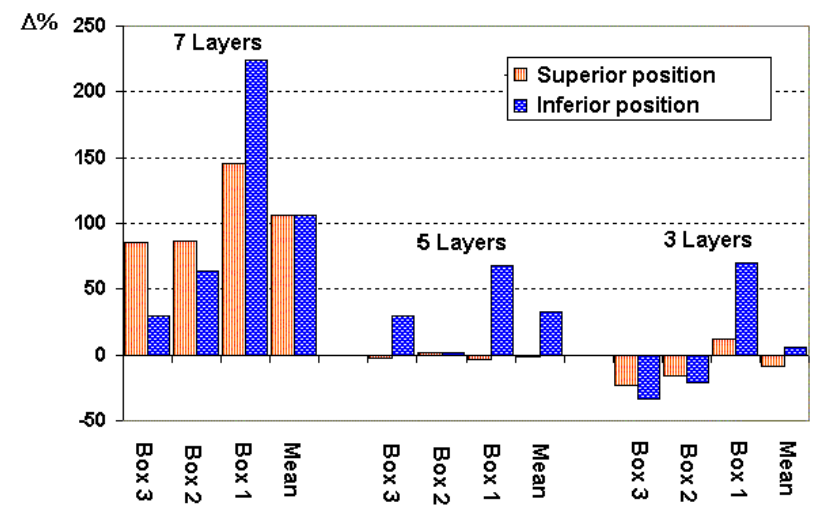

Figure 8. Difference between the values of Nusselt calculated from the Eqs. (7) and (8) and the values obtained from experimental results for the transducer located in the superior and inferior layers not considering the temperature effect.

In the average, the values obtained from correlations based on the hydraulic diameter for these configurations were those that supplied the best results when compared with experimental results obtained from measures using the metallic transducer mainly for assays with 5 and 3 layers and transducer located in the superior layers of the arrays. For these arrays, the use of the correlations resulted in values with a average percentile difference $9,1 \%$ lower when compared with the experimental results. For the transducer located in inferior layers of the arrays of 7 layers this difference becomes sharper, above of $100 \%$. 
Table 4. Experimental values for the effective heat transfer coefficients obtained from the cooling curves of the metallic transducer.

\begin{tabular}{|c|c|c|c|c|c|c|c|c|}
\hline \multicolumn{9}{|c|}{ Effective heat transfer coefficients $\left(\mathrm{W} / \mathrm{m}^{2{ }^{0} \mathrm{C}}\right)$} \\
\hline Position & Layer & Box & $\mathbf{T}_{\text {air }}\left({ }^{\circ} \mathbf{C}\right)$ & $\mathbf{h}_{\text {effective }}$ & $\mathbf{T}_{\text {air }}\left({ }^{\circ} \mathrm{C}\right)$ & $\mathbf{h}_{\text {effective }}$ & $\mathrm{T}_{\text {air }}\left({ }^{\circ} \mathrm{C}\right)$ & $\mathbf{h}_{\text {effective }}$ \\
\hline Superior & 7 & 3 & $-27,7$ & 17,86 & $-24,7$ & 16,34 & $-17,0$ & 13,77 \\
\hline Inferior & 7 & 3 & $-26,7$ & 16,32 & $-24,9$ & 15,48 & $-17,6$ & 15,00 \\
\hline Superior & 7 & 2 & $-27,2$ & 14,60 & $-24,8$ & 16,03 & $-17,0$ & 15,76 \\
\hline Inferior & 7 & 2 & $-27,4$ & 13,78 & $-25,4$ & 13,86 & $-16,7$ & 9,34 \\
\hline Superior & 7 & 1 & $-27,0$ & 10,47 & $-25,6$ & 11,06 & $-16,3$ & 13,73 \\
\hline Inferior & 7 & 1 & $-28,1$ & 9,13 & $-24,6$ & 4,15 & $-16,3$ & 7,71 \\
\hline Superior & 5 & 3 & $-30,0$ & 28,84 & $-23,9$ & 22,42 & $-16,5$ & 18,27 \\
\hline Inferior & 5 & 3 & $-31,0$ & 9,47 & $-22,7$ & 13,01 & $-16,8$ & 7,71 \\
\hline Superior & 5 & 2 & $-30,6$ & 27,77 & $-23,2$ & 20,92 & $-17,8$ & 16,62 \\
\hline Inferior & 5 & 2 & $-30,8$ & 9,27 & $-22,8$ & 14,48 & $-17,9$ & 13,99 \\
\hline Superior & 5 & 1 & $-30,5$ & 28,01 & $-23,8$ & 20,24 & $-15,0$ & 18,58 \\
\hline Inferior & 5 & 1 & $-30,4$ & 5,05 & $-23,4$ & 9,16 & $-16,3$ & 8,40 \\
\hline Superior & 3 & 3 & $-26,4$ & 22,94 & $-23,8$ & 18,82 & $-18,0$ & 25,87 \\
\hline Inferior & 3 & 3 & $-28,2$ & 10,73 & $-22,8$ & 17,53 & $-16,4$ & 24,49 \\
\hline Superior & 3 & 2 & $-26,7$ & 22,02 & $-22,9$ & 19,51 & $-17,8$ & 19,61 \\
\hline Inferior & 3 & 2 & $-30,2$ & 13,71 & $-22,7$ & 17,61 & $-17,0$ & 16,65 \\
\hline Superior & 3 & 1 & $-28,4$ & 19,18 & $-23,8$ & 17,90 & $-17,5$ & 11,21 \\
\hline Inferior & 3 & 1 & $-29,2$ & 5,75 & $-22,8$ & 8,78 & $-17,2$ & 5,78 \\
\hline
\end{tabular}

Table 5. Analysis of variance for the results of the experimental effective heat transfer coefficients presented in the Table 4.

\begin{tabular}{|l|c|c|c|c|c|c|}
\hline \multicolumn{1}{|c|}{ Source } & S.S. & D.F. & M.S. & F-statistic & F $_{\text {tab. }}$ & Level-p \\
\hline 1. Position of the Transd. & 677,415 & 1 & 677,415 & 72,931 & 7,41 & $0,01^{*}$ \\
\hline 2. Position of the box & 155,739 & 2 & 77,864 & 8,383 & 5,26 & $0,01^{*}$ \\
\hline 3. Number of layers & 69,578 & 2 & 34,789 & 3,745 & 3,27 & $0,05^{*}$ \\
\hline 4. Temperature of air & 6,709 & 2 & 3,355 & 0,361 & 2,46 & 0,1 \\
\hline 5. $(1 \times 2)$ & 20,487 & 2 & 10,243 & 1,103 & 2,46 & 0,1 \\
\hline 6. $(1 \times 3)$ & 104,088 & 2 & 52,044 & 5,603 & 5,26 & $0,01^{*}$ \\
\hline 7. $(1 \times 4)$ & 50,680 & 2 & 25,340 & 2,728 & 2,46 & $0,1^{*}$ \\
\hline 8. $(2 \times 3)$ & 20,271 & 4 & 5,068 & 0,547 & 2,11 & 0,1 \\
\hline 9. Resídual & 334,382 & 36 & 9,288 & & & \\
\hline 10. Total & 1439,34 & 53 & & & & \\
\hline
\end{tabular}

* Significant with level p of probability. 


\section{CONCLUSIONS}

In Configurations containing different arrays of product layers, the effective heat transfer coefficients vary in different positions between the superior and inferior layers of arrays in the boxes. The relative percentile variation between the evaluated values in these positions was of 10 to $70 \%$ depending on the experimental configuration, being the biggest variation observed for arrays with 5 layers of product and the minors for arrays of 7 layers. These values had been justified in terms of the free area for the airflow in the different configurations and of the contact of the cooling air stream with the metallic transducer used in the measures.

Analyses experimental and theoretical of the effect of the cooling air temperature indicate that these do not exert significant influences on the values of the effective heat transfer coefficients in the range of described conditions by the experimental planning.

The developed correlations are based on the hydraulic diameter of rectangular ducts existing between the boxes and are appropriate for arrays of 3 and 5 layers where the rectangular ducts existing between the boxes of the piling up and available air flow area are defined. For these configurations, the percentile average differences was around 9.11\% when the values were compared with the experimental results for the transducer located in the superior position of the layers arrays and 34\% when located in the inferior position. Arrays of 7 layers had presented a great difference (above of $100 \%$ ) between the experimental and predicted values. This configuration is an extreme situation, with excess of product amount offering great resistance to the air pass by the product and making difficult the definition of the cooling airflow conditions. This configuration is not recommended and it is not applied in the practical with commercial air blast freezers.

\section{ACKNOWLEDGEMENTS}

Acknowledgements are made to $\mathrm{CNPq}$ (Conselho Nacional de Desenvolvimento Científico e Tecnológico) for financially supporting this study.

\section{REFERENCES}

Arce, J. A. and Sweat, V. E., 1980, "Survey of published heat transfer coefficients encountered in food refrigeration processes". ASHRAE Transactions, Vol.82, No. 6, pp.235-260.

Chavarria, V. M. and Heldman, D. R., 1984, "Measurement of convective heat transfer coefficients during food freezing processes", Journal of Food Science. Vol. 49, pp.810-814.

Cleland, A. C., 1990, " Food refrigeration process. Analysis, design and simulation", Elsevier Applied Science: London and New York, 284p.

Cleland, D. J.; Cleland, A. C. and Jones, R. S., 1994, "Collection of accurate experimental data testing the performance of simple methods for food freezing time prediction", Journal of Food Process Engineering, Vol.17, pp.93-119.

Kondjoyan, A.; Daudin, J. D. and Bimbenet, J. J., 1993, "Heat and mass transfer coefficients at the surface of elliptical cylinders placed in a turbulent air flow", Journal of Food Engineering, Vol. 20, pp. 339-367.

Kondjoyan, A. and Daudin, J. D., 1997, "Heat and mass transfer at the surface of a pork hindquater", Journal of Food Engineering, Vol. 32, pp.225-240.

LeBlanc, D. I.; Kok, R. and Timbers, G. E., 1990a, "Freezing of a parallelepiped food product. Part 1. Experimental determination", International Journal of Refrigeration, Vol.13, pp.371-378.

LeBlanc, D. I.; Kok, R. and Timbers, G. E., 1990b, "Freezing of a parallelepiped food product. Part 2. Comparison of experimental and calculated results", International Journal of Refrigeration, Vol.13, pp.371-392.

Lind, I.,1988, "Surface heat transfer in thawing by forced air convection", Journal of Food Engineering, Vol.7, pp.19-39.

Mannaperuma, J. D., Singh, R. P. and Reid, D. S.,1994a, "Effective surface heat transfer coefficients encountered in air blast freezing of whole chicken and chicken parts, individually and in packages", International Journal of Refrigeration, Vol. 17, No. 4, pp.263-272.

Mannaperuma, J. D., Singh, R. P. and Reid, D. S.,1994b, "Effective surface heat transfer coefficients. 